\title{
CONSENSO SOBREPOSTO E ESTABILIDADE INTERNACIONAL
}

\author{
Overlapping consensus and international stability'
}

Consenso superpuesto y estabilidad internacional

Fernando Nunes Oliveira ${ }^{2}$

Universidade Federal de Pelotas, Pelotas, RS, Brasil.

\section{Resumo}

Apresentamos aqui uma introdução à teoria que denominamos Legitimidade como Equidade. Tal teoria tem como finalidade dar suporte à tese de que a estabilidade internacional oferecida pela busca de um consenso sobreposto (moral) de Estados, que se procura atingir pelo método do equilíbrio reflexivo, é mais eficiente do que quatro alternativas que denomino "standard" nas práticas internacionais e na teoria que informa práticas políticas. São elas: Estabilidade oferecida por uma instituição internacional com o uso exclusivo da força; Estabilidade oferecida por uma balança de poder entre potências; Estabilidade oferecida por uma balança de poder buscada como um valor compartilhado; Paz imposta hegemonicamente. Consideramos as

\footnotetext{
O presente artigo tem por intuito introduzir a teoria que começamos a desenvolver em nossa tese de doutorado e que tem sido objeto de investigação em nossas pesquisas. $\mathrm{O}$ artigo possui partes em comum com a mencionada tese. Essa, por sua vez, está mencionada nas referências e disponível (mas não publicada) eletronicamente em: http://tede2.pucrs.br/tede2/handle/ tede/7219. Acesso em: 28mar. 2019.

2 Doutor em Filosofia pela Pontifícia Universidade Católica do Rio Grande do Sul (PUCRS), Porto Alegre,RS, Brasil.Estágio sanduíche na Universidade de Princeton, Estados Unidos da América, com pesquisa fomentada pela Fulbright/CAPES.Mestre em Filosofia pela UFPEL, Pelotas (RS), Brasil. Bacharel em Direito e Filosofia.Professor do curso de Filosofia a distância no Departamento de Filosofia do Instituto de Filosofia, Sociologia e Política da Universidade Federal de Pelotas (UFPEL), Pelotas,RS, Brasil. ORCID: http://orcid.org/0000-0002-1086-2056. E-mail: fernandon.oliveira@yahoo.com.br
} 
teorias do realismo político nas Relações Internacionais como aquelas a partir das quais podem ser levantadas as maiores objeções em relação à nossa proposta. Logo, temos como ponto de partida argumentos presentes nas obras de relevantes autores dessa tradição de pesquisa para dar ensejo inicial às questões que deveriam ser levadas em conta pela Legitimidade como Equidade. Em nossa proposta fazemos uso dos conceitos de consenso sobreposto e do equilíbrio reflexivo de maneira análoga àquela como aparecem na Justiça como Equidade de John Rawls estabelecendo como ponto fixo provisório os valores do Jus Cogens Internacional e uma virtude correlata à prudência aristotélica a ser desenvolvida por agentes internacionais.

Palavras-chave: Consenso Sobreposto. Equilíbrio Reflexivo. Estabilidade Internacional. Realismo Político.

\section{Abstract}

Here we present an introduction to the theory that we call Legitimacy as Fairness. The purpose of this theory is to support the thesis that the international stability offered by the searching for a overlapping consensus of states, which is sought by the method of reflexive equilibrium, is more efficient than the four alternatives I call "standard" to international practices and to theories that inform policies. They are: Stability brought by an international institution with exclusive use of force; Stability brought by a balance between powers; Stability brought by a balance of power sought as a shared value; An hegemonically imposed peace. We see the theories of political realism in international relations as the ones from which can be raised the greatest objections to our proposal. Therefore, we made use of arguments that are present in the works of relevant authors of this tradition of research as starting point to the issues that should be taken into account by the Legitimacy as Fairness. In our proposal we make use of the concepts of overlapping consensus and reflexive equilibrium in a way analogous to which they appears in Rawls's Justice as Fairness, establishing as provisional values the ones of International Jus Cogens and a virtue to be developed by international agents that is related to Aristotelian phronesis.

Keywords: Political Realism. International Stability.Overlapping Consensus. Reflective Equilibrium.

\section{Resumen}

Presentamos en la siguiente reflexión una introducción a la teoría que denominamos legitimidad como Equidad. Tal teoria tiene como objetivo apoyar la tesis de que la estabilidad internacional ofrecida por la búsqueda de una consenso superpuesto (moral) de los Estados, que busca alcanzar por el método de lequilibrio reflexivo, es más eficiente 
que las cuatro alternativas que denomino "standard" en las prácticasinternacionales y en la teoría que informa prácticas políticas. Son las seguientes: Estabilidad ofrecida por una institución internacional com el uso exclusivo de la fuerza; Estabilidad ofrecida por um equilibrio de poder entre potencias; La estabilidad ofrecida por unequilibrio de poder buscado como valor compartido; La paz imposta hegemónicamente. Consideramos lasteoríasdel realismo político enlas relaciones internacionales, como las de las que se pueden plantear las mayores objeciones enrelación con nuestra propuesta. Por lo tanto, tenemos como punto de partida argumentos presentes las obras de autores relevantes de esta tradición de investigación para dar la oportunidad inicial a las cuestiones que deberían ser tomadas encuenta por la legitimidad como Equidad. En nuestra propuesta utilizamos los conceptos de consenso superpuesto y equilibrio reflexivo de una manera análoga a la que aparecen en la justicia como Equidad de John Rawls estableciendo como punto fijo provisorio los valores de Jus Cogens International y una virtud corelata a la ideia de prudencia aristotélica que desarrollada por los agentes internacionales.

Palabras clave: Consenso Solapado. Equilibrio Reflexivo. Estabilidad Internacional. Realismo Político.

\section{Introdução}

Propomos que a estabilidade internacional oferecida pela busca de um consenso sobreposto (moral) ${ }^{3}$ de Estados, que se procura atingir pelo método do equilíbrio reflexivo, usada para o ambiente internacional de maneira análoga àquele uso que Rawls faz destes conceitos para sociedades democráticas na Justiça como Equidade4, é mais eficiente ou, dados os arranjos internacionais correntes, pode ser alcançada com mais facilidade, do que aquelas que denominamos alternativas "standard" de estabilidade internacional.

3 Não fazemos aqui diferença entre os conceitos de ética e moral, logo, usamos os temos como intercambiáveis.

4 No presente artigo fizemos uso de Justiça como Equidade (com iniciais maiúsculas) para nos referirmos à teoria de justiça elaborada por Rawls (e que tornou-se célebre com a publicação da obra Uma teoria da justiça em 1971, tendo sido apresentada de forma reformulada em $O$ liberalismo político e justiça como equidade:uma reformulação) e justiça como equidade (com iniciais minúsculas) para designarmos o uso comum da expressão. De forma semelhante Fizemos uso de $O$ direito dos povos (em itálico) para nos referir a obra em si, de Direito dos Povos (sem itálico, com iniciais maiúsculas) para nos referir a teoria de justiça internacional desenvolvida por Rawls nela, e direito dos povos (sem itálico, com iniciais minúsculas) para referir-nos de maneira genérica a uma legislação internacional. 
São as alternativas de estabilidade dentro dessa perspectiva "standard", a nosso ver, as seguintes: estabilidade oferecida por um governo internacional ou instituição internacional com o uso exclusivo da força; estabilidade oferecida por uma balança de poder entre potências sem compartilhamento de uma moral comum; estabilidade oferecida por uma balança de poder buscada como um valor compartilhado; e paz imposta hegemonicamente.

A defesa da tese que propomos acima necessita de uma série de considerações prévias e do auxílio de uma teoria política normativa, com base em argumentos filosóficos, que faça um uso específico dos conceitos do consenso sobreposto e do equilíbrio reflexivo para dar-lhe suporte e justificação adequada. É a uma breve apresentação de um rascunho de uma teoria com as características descritas acima que dedicamos o presente artigo.

\section{Definição e ponto de partida teórico}

À teoria com as características que descrevemos acima e iremos apresentar aqui, damos o nome provisório de Legitimidade como Equidade.

Consideramos as teorias do realismo político nas Relações Internacionais ${ }^{5}$ como aquelas a partir das quais podem ser levantadas as maiores objeções em relação à nossa proposta, tendo estas objeções, assim pensamos, um caráter cético semelhante a um ceticismo moral. Desta maneira estabelecemos como ponto de partida justamente argumentos presentes no pensamento destes teóricos para dar ensejo inicial às questões que deveriam ser levadas em conta pela Legitimidade como Equidade. Para esse fim escolhemos entre os pensadores realistas três renomados representantes desta escola, a saber: Edward Hallet Carr, Hans Morgenthau e Kenneth Waltz.

No século XX o estudo das relações entre os Estados se tornou uma disciplina autônoma denominada Relações Internacionais (ou R.I.). Para a

\footnotetext{
5 No presente Paper, fazemos uso do termo com iniciais maísculas sempre que nos referimos à disciplina de Relações Internacionais e com iniciais minúsculas para designar um uso diverso a esse.
} 
investigação das Relações Internacionais foram estabelecidos vários modelos teóricos que por sua vez possuem diferentes abordagens sobre as principais questões relativas aos temas das R.I. (segurança, liberdade, ordem, justiça e bem-estar). O realismo político veio a se tornar um dos mais respeitados e influentes destes modelos e dentro da tradição de teorias políticas de Relações Internacionaisé, conforme afirmado por Jackson e Sorensen, normalmente dividido entre as abordagens clássicas (e neo-clássicas) que "enfatizam os aspectos normativos do realismo assim como os empíricos"(JACKSON; SORENSEN, 2007, p.101) e as abordagens contemporâneas neo-realistas, em que os autores seguem "uma análise científica social das estruturas e dos processos da política mundial" (JACKSON; SORENSEN, 2007, p.101).

Ao longo da história muitas pessoas são apontadas como tendo se portado de acordo com prescrições realistas ou tendo teorizado aqueles preceitos que dariam base e inspiração ao pensamento realista. Notavelmente o historiador grego Túcidedes e os Filósofos Maquiavel e Tomas Hobbes são vistos como tendo inspirado a escola realista, mas esta lista poderia estender-se muito mais se for realizado um levantamento histórico acerca de conceitos como a balança de poder, as razões de estado, bem como a visão egoísta da natureza humana ${ }^{6}$.

Tendo ganhado força após a primeira guerra mundial, inicialmente o objetivo central da investigação das Relações Internacionais era evitar que um novo conflito de larga escala com proporções catastróficas ocorresse (JACKSON; SORENSEN, 2007, p. 62). As razões da guerra e os atos dos envolvidos no conflito passaram a ser investigados predominantemente por uma teoria acadêmica com bases em ideias liberais. Tendo percebido a facilidade com que os sistemas autocráticos entraram em conflito, até que ponto estes estavam dispostos a levá-lo e influenciados pelas ideias do

6 Para uma obra com grande quantidade de informações e nomes históricos seguindo (ao menos em grande parte) uma abordagem realista sobre estes conceitos ao longo do tempo, ver HASLAM, John. A necessidade é amaior virtude: opensamento realista nas relações internacionais. 
então presidente norte-americano Woodrow Wilson ${ }^{7}$ (e com suas pesquisas apoiadas por ele e pelo governo inglês), pensadores liberais apresentaram "algumas ideias nítidas sobre como evitar desastres no futuro; por exemplo, por meio da reforma do sistema internacional e das estruturas nacionais de países autocráticos" (JACKSON; SORENSEN, 2007, p. 64). Essa primeira investigação de cunho liberal das Relações Internacionais estabeleceu certas ideias marcantes, como a de que o estabelecimento de uma liga de povos aumentaria o comprometimento institucional entre eles, e a noção de que a guerra pode trazer benefícios financeiros e glória ao vencedor é um equívoco, uma vez que a guerra impede o livre comércio internacional, este sim capaz de gerar desenvolvimento ${ }^{8}$ além de colaborar para o estabelecimento efetivo de um direito internacional, uma vez que as relações tornam os países cada vez mais interdependentes (JACKSON; SORENSEN, 2007, p. 65-67).

Os ideais da escola liberal fracassaram em evitar os acontecimentos que levaram à segunda guerra mundial. A perspectiva realista, mais pragmática e menos ideológica, começou a receber maior prestígio e em pouco tempo se estabeleceu como o mais influente modelo acadêmico para política internacional.

Mesmo antes de o realismo político ter estabelecido sua influência acadêmica como um modelo de Relações Internacionais E.H Carr publicou sua obra Os vinte anos de crise (de 1939) e nela fez uma dura crítica ao liberalismo político nas Relações Internacionais (que ele chama "utopismo") (KORAB-KARPOWICZ, 2010) e ao modo como as grandes potências vinham administrando a crise política na Europa. Ele teorizou que no campo interna-

\footnotetext{
7 Woodrow Wilson foi presidente americano de 1913 a 1921. Ele apresentou seu programa de 14 pontos para a política exterior para o período pós-guerra em janeiro de 1918, em um discurso para o congresso dos Estados Unidos. Seu programa era um programa de paz e apresentava o término da diplomacia secreta, a redução dos armamentos até o nível em que fosse necessário para manter a segurança doméstica, a autodeterminação dos povos e a formação de uma liga de povos (Cf. JACKSON; SORENSEN, 2007, p. 65). Wilson acreditava na possibilidade da paz democrática (a ideia de que as democracias não fazem guerras umas com as outras) e que um crescimento das democracias na Europa diminuiria a possibilidade de líderes autocráticos surgirem. Além disso, uma liga de povos deveria estabelecer entre eles ligações institucionais mais fortes (CF. JACKSON; SORENSEN, 2007, p. 65).

8 Esta ideia é estabelecida, sobretudo por Norman Angell, em sua obra de 1919 The Greatllusion (Cf. JACKSON; SORENSEN, 2007, p. 66).
} 
cional há Estados que possuem o poder e controlam a política internacional e alguns Estados que estão crescendo em poder e podem fazer exigências, mas que ainda não participam do controle da política internacional. Tendo como inspiração para sua análise a ideia marxista do conflito entre classes ele estabelece que é necessário que os que estão no poder sejam hábeis em fazer concessões cuidadosas para que mantenham-se com ele, Carr conjecturou que fora a habilidade da Inglaterra de administrar de forma razoável o poder que exercia sobre os outros e a habilidade de fazer concessões razoáveis que a manteve como a potência dominante durante o século XIX e o início do século XX. Como era uma administradora razoável do poder (além de muito poderosa) o custo de opor-se a ela poderia ser maior do que os benefícios que tal oposição poderia trazer.

A obra de Carr foi superada em importância e influência por Política entre as nações: a luta pelo poder e pela paz de Hans Morgenthau. Morgenthau havia teorizado que a vontade de dominar é um elemento intrínseco da natureza humana, estando presente nos mais diversos níveis das relações humanas. Preocupado em gerar uma independência científica para a ciência política ele estabelece a vontade de dominar como a chave para a análise de situações políticas, incluindo as relações de política internacional. A vontade de dominar pode se apresentar de formas mais violentas ou mais contidas. Dentro de um ambiente com mais restrições, como aquele presente dentro de um Estado com uso exclusivo da força, a vontade de dominar encontra meios mais "saudáveis" de expressão. O ambiente internacional, no entanto, seria bem complicado. Embora tenha havido momentos na história em que as relações entre os povos atingiram maior estabilidade, na segunda metade do século XX elas eram muito perigosas. Morgenthau considerava que em boa parte da modernidade as relações entre as potências europeias eram particularmente estáveis, pois os valores compartilhados entre as potências (valores da nobreza e a ideia de que eram nações civilizadas e civilizadoras) europeias faziam com que todos buscassem manter a balança de poder. No século XX, com o declínio do poder da nobreza europeia, também havia caído sua capacidade de man- 
ter os valores que haviam gerado tal estabilidade. Com a falta de valores compartilhados e, dada a forma que os nacionalismos adquiriram no século $X X$, manter a paz internacional, mesmo uma paz relativa, havia se tornado uma tarefa difícil. Se em um passado recente os nacionalismos tentavam garantir a existência de um povo e sua identidade, bem como sua posse sobre um território, na ausência de valores internacionais comuns, provocada pela queda dos valores da nobreza europeia, os nacionalismos agora haviam assumido uma faceta muito mais nefasta. Cada nação havia passado a ver seus próprios valores como aqueles válidos internacionalmente, e a busca pelo poder trouxe consigo a tentativa de imposição dos valores de uma nação para as outras. Este fator fazia, para Morgenthau, com que a guerra fria fosse especialmente perigosa, pois agora, pela primeira vez na história da humanidade, o homem tinha a capacidade de fazer uma guerra de destruição total. Morgenthau via como a única saída racional para este problema o estabelecimento de uma instituição internacional com o uso exclusivo da força ${ }^{9}$. A instauração de uma instituição com estes moldes, não seria, no entanto, possível ou desejável. A ausência de valores internacionais compartilhados faria com que tal instituição fosse um Estado despótico e artificial, sujeito a revoltas de cunho nacionalista. Ele propunha uma solução paliativa que consistia em investir na diplomacia e na liberdade diplomática, pois os diplomatas profissionais, possuindo suas técnicas sutis, desvinculados de exigências nacionalistas ou populares, poderiam encontrar um espaço de diálogo, ainda que temporário.

Com relação à teoria de Waltz, consideraremos aqui duas obras. São elas (em ordem cronológica) Man, state and war (publicada pela primeira vez em 1959). e Theory of international politics (publicada pela primeira vez em 1979). Em Man, state and war, Waltz levanta a hipótese de que as teorias que até então tentaram apontar as causas do conflito internacional (quer fossem filosóficas, psicológicas ou com origem nas ciências sociais ou comportamentais) haviam falhado, pois tinham deixado de levar em conta

\footnotetext{
9 Para Morgenthau, uma instituição como esta não seria outra coisa que não um Estado mundial.
} 
aspectos relevantes. Para ele, haveria três aspectos relevantes a se considerar na investigação das causas do conflito internacional; aquele relativo à natureza ou comportamento humano, aquele relativo à organização institucional dos Estados e aquele relativo à maneira como os Estados estão frente uns aos outros em um ambiente de anarquia internacional. Ele chama a cada um destes três aspectos de imagens ${ }^{10}$, e afirma que uma teoria que deixe de levar em consideração, na devida medida, cada uma das três imagens para investigar a causa dos conflitos e propor uma solução para eles estará fadada ao fracasso.

Embora diga que alguma importância é devida aos três aspectos o autor tenta deixar claro que é possível que se estabeleça uma teoria de terceira imagem, de longe a que era, até então, a menos usada. Se dentro das outras imagens temos teorias que caracterizam de maneira diferente a natureza humana ou a forma institucional ideal que possamos colocar fim ao conflito internacional, na terceira imagem não há margem para variação em decorrência do fato de os Estados estarem uns frente aos outros em um ambiente anárquico, o que tornaria o conflito uma grande possibilidade de forma permanente, de maneira que todos os Estados devem sempre se preparar da melhor maneira possível. A solução seria uma instituição internacional com uso exclusivo da força. Essa falta de variedade de alternativas para resolução do conflito, leva a uma descrição mais fixa de comportamentos e possibilidades de ação do que aquela apresentada pelas outras imagens"1 .

\footnotetext{
10 Sendo teorias de primeira imagem aquelas que localizam a causa do conflito na natureza humana, de segunda imagem aquelas que localizam as causas do conflito na organização interna dos Estados e de terceira imagem aquelas que consideram como causa do conflito a situação de insegurança dos Estados gerada por estarem inseridos em um ambiente anárquico.

$"$ Teóricos de primeira imagem, ainda que localizem as causas para o conflito na natureza ou comportamento do homem, podem ter muitas diferenças na sua visão de como é a natureza humana e quais medidas devem ser tomadas para que o conflito tenha fim. Alguns deles argumentam, por exemplo, que com o desenvolvimento correto da racionalidade não teríamos mais conflitos, outros defendem que os conflitos acabariam se desenvolvêssemos uma forma ideal de comunicação. Há ainda os pessimistas de primeira imagem, que entendem que a causa do conflito está na natureza humana, e que esta, sendo imutável, faz com que os conflitos nunca possam acabar. Com relação à segunda imagem temos uma ampla variação a respeito de qual seria a forma adequada do Estado para que os conflitos acabassem, de comunistas como Marx e Lênin, que consideram que todos os conflitos acabariam se todos os estados fossem socialistas, aos liberais como Woodrow Wilson, que considera as instituiçõos democráticas como a medida necessária para que o conflito deixasse
} 
Se em Man, state and war, Waltztenta mostrar a possibilidade de uma teoria da terceira imagem e definir as características do ambiente internacional, em Theory of international politics vemos sua tentativa de estabelecer uma teoria de terceira imagem de forma independente de fatores relacionados às outras duas imagens. Waltz propõe uma teoria sistêmica que é estabelecida utilizando como inspiração a teoria microeconômica da firma, com Estados no lugar de empresas, disputando o poder internacional para manter sua existência da mesma maneira que empresas disputam espaço no mercado para aumentar seus lucros, funcionando em um sistema internacional da mesma maneira que as firmas funcionam dentro do sistema econômico. Ele considera agora quase irrelevantes aspectos das unidades (os Estados) na determinação da maneira como estas irão se comportar, encontrando-se a efetividade de seu comportamento determinada pelo próprio sistema e sendo este o fator relevante a ser levado em consideração nas análises da política internacional.

Tendo em vista os argumentos expostos pelos autores mencionados acima em suas respectivas obras tentamos esboçar aqui, com a Legitimidade como Equidade, uma proposta de estabilidade internacional mais efetiva do que aquelas que eles consideram possíveis (que recaem, de uma maneira ou outra, dentro das alternativas "standard") e que responda às considerações a respeito das três imagens como apresentadas por Waltz em Man, state and war. À ideia de Carr de que a Inglaterra não teve seu poder contestado muitas vezes pois sabia administrá-lo com moderação, acrescentamos como fator de estabilidade à administração do poder com moderação a percepção de que os atos podem ser considerados legítimos pois estão de acordo com valores morais compartilhados internacionalmente. Concordamos com Morgenthau (2003) quando ele afirma que um governo mundial não seria desejável agora, pois não há valores compartilhados de maneira forte o suficiente para dar suporte ao seu estabelecimento. Também conside-

de existir. A terceira imagem não teria, para Waltz, uma variedade de soluções e só pode chegar ao fim com o estabelecimento de uma instituição mundial com uso exclusivo da força. 
ramos o investimento nos diplomatas uma solução paliativa. Propomos, entretanto, que há valores presentes hoje no campo internacional que, se usados da forma correta, podem desempenhar uma função semelhante aos valores da nobreza europeia na modernidade e servir como elementos para uma estabilidade satisfatória, que poderia ser ainda mais eficiente se estes valores puderem ser absorvidos e garantidos pela moral nacional de várias nações e passar a fazer parte de seus valores nacionais. Aceitamos a crítica de Waltz quanto à impossibilidade de uma teoria que investigue as causas do conflito (e que tente propor alguma solução para ele) não apresentar uma resposta satisfatória se não levar em consideração as três imagens que o autor estabelece. Por isso a Legitimidade como Equidade apresentará (aqui de forma resumida e inicial) uma solução para o conflito que perpassasse todas as três imagens de Waltz.

\section{O que faz a Legitimidade como Equidade ser atrativa para os Estados?}

Os agentes dos Estados podem reconhecer racionalmente que a cooperação pode trazer melhores resultados do que a não cooperação. Para terem melhores ganhos os Estados deveriam então buscar estabelecer um ambiente estável em que a cooperação possa ocorrer com mais frequência. Entretanto, como modelo teórico, nos parece que o realismo político ergue três obstáculos teóricos para a cooperação internacional. São eles: a instabilidade gerada pela disputa advinda da divergência de valores e a visão de cada Estado de que seus valores nacionais são os certos ou melhores e devem valer internacionalmente; a ideia da necessidade de aumento de poder; o receio em relação ao aumento de poder dos outros Estados e as decorrentes preocupações com poder relativo.

A Legitimidade como Equidade tenta apresentar uma solução para o primeiro obstáculo, pois cremos que ao diminuir a magnitude dele a importância dos outros dois será indiretamente diminuída. Tal afirmação precisa ser justificada. 
O segundo e terceiro obstáculo apresentam sua mais forte fundamentação em um argumento apresentado por Waltz em Man, state and war. Na referida obra, na tentativa de argumentar a favor da possibilidade de estabelecer uma teoria de terceira imagem, Waltz faz uso de um argumento que pensa ter bases no Discurso sobre a origem e os fundamentos das desigualdades entre os homens (publicada originalmente em 1755) de Rousseau. Ele é baseado na caça ao veado descrita por Rousseau na referida obra. Na situação hipotética da caça ao veado, Rousseau descreve homens no estado de natureza que uniram forças para apanhar um veado, mas um dos homens abandona a caçada para apanhar uma lebre que havia avistado. $O$ veado traria ganhos individuais maiores do que a lebre, mas ainda assim um dos caçadores abandona o empreendimento cooperativo. Waltz afirma que embora seja simples, se essa alegoria for usada como analogia para a situação que os Estados encontram-se uns frente aos outros no campo internacional, suas implicações são muito grandes, pois a um só tempo, possibilitaria uma teoria da terceira imagem e mostra a característica de insegurança, demonstrada pela impossibilidade de confiança, à qual estão submetidas as relações entre Estados, por estes estarem em um ambiente anárquico. Como Waltz, acreditamos ser possível uma teoria da terceira imagem, mas, com base no argumento utilizado por analogia à caça ao veado de Rousseau, não podemos concordar com a característica de insegurança desta imagem na mesma intensidade proposta por Waltz em Man, state and war ou na possibilidade de sua total independência teórica de outros fatores, usada para dar base para as teorias sistêmicas. Parte de nossa recusa ocorre por que entendemos que a leitura de Waltz das causas que levam os homens descritos na caça ao veado a não cooperar está errada. $\mathrm{Na}$ leitura de Waltz um deles não coopera por causa da insegurança de que os outros façam o mesmo. Em nossa opinião, na caça ao veado como descrita por Rousseau eles não cooperam por que eles ainda não possuem a capacidade de avaliar as perdas de ganhos futuros decorrentes de suas ações (uma capacidade muito evidente na espécie humana), sendo movi- 
dos puramente pelo instinto de satisfazer suas necessidades imediatas. $\mathrm{O}$ conteúdo da referida passagem textual de Rousseau é o seguinte:

Eis como os homens puderam, insensivelmente, adquirir uma ideia grosseira dos compromissos mútuos e da vantagem de os cumprir, mas somente na medida em que podia exigi-lo o interesse presente e sensível; porque a previdência nada era para eles; e, longe de se ocuparem com um porvir afastado, nem mesmo pensavam no dia seguinte. Se se tratava de pegar um veado, cada qual sentia bem que, para isso, devia ficar no seu posto; mas, se uma lebre passava ao alcance de algum, é preciso não duvidar de que a perseguia sem escrúpulos e, uma vez alcançada a sua presa, não lhe importava que faltasse a dos companheiros (ROUSSEAU, 2001, p. 95-96).

Cremos que a presença da simples capacidade de avaliar ganhos futuros e um passado compartilhado já seria suficiente para tornar esta relação não tão determinada, o que certamente também se aplicaria ao uso análogo do argumento para as relações entre Estados.

Se a característica de insegurança na relação dos caçadores é diminuída em certo grau com a simples adição da capacidade de cálculo sobre ganhos futuros e experiências partilhadas entre os caçadores (dependendo de como estas transcorreram), cremos que maior ainda seria a diminuição da insegurança se os caçadores possuíssem capacidade moral e valores compartilhados. Acreditamos que essa ideia também pode ser transposta para a analogia da relação entre Estados. Isso mostra que querer a efetividade e independência de uma teoria sistêmica na medida em que Waltz deseja não é possível, pois fatores além daqueles trazidos pela situação de anarquia também são relevantes. Logo, uma solução com base em valores internacionais (que lida diretamente com o primeiro dos obstáculos realistas à cooperação que havíamos elencado) certamente pode diminuir a relevância dos outros dois. 
Dessa forma, a Legitimidade como Equidade propõe uma estabilidade com bases morais. Para que essa tarefa tenha viabilidade são importantes os conceitos do consenso sobreposto e do equilíbrio reflexivo. Usamos esses conceitos de maneira análoga ao uso que Rawls faz deles na Justiça como Equidade.

\section{Do uso diverso do consenso sobreposto e do equilíbrio reflexivo}

Rawls argumenta que em sociedades democráticas há uma série de doutrinas abrangentes que possuem visões de mundo, crenças e valores diferentes. Se, apesar disso, uma doutrina abrangente for capaz de tolerar a existência das outras em um âmbito público, assegurando junto às demais doutrinas abrangentes um acordo moral acerca dos valores que são publicamente compartilhados por sua sociedade, esta doutrina será considerada uma doutrina abrangente razoável. O consenso sobreposto é o elemento que permitiria um grau elevado de estabilidade ${ }^{12}$ institucional dentro de uma sociedade democrática, sendo uma expressão forte daqueles valores em torno dos quais existe um acordo público, compartilhados no âmbito público e para resolver questões públicas, independente dos valores individuais que cada um possa ter por professar uma doutrina abrangente em particular.

O equilíbrio reflexivo é um modo indutivo de justificação para crenças públicas que permite que sejam feitas as correções e ajustes de juízos de acordo com os valores partilhados publicamente. Ele se apresenta em duas

\footnotetext{
12 Referimos-nos aqui a um elevado grau de estabilidade porque o consenso sobreposto seria a expressão mais forte de um acordo moral em torno de valores publicamente compartilhados, garantindo normas para serem aplicadas à estrutura básica de uma sociedade, sendo uma forma mais forte do que um consenso constitucional, que garantiria alguns princípios de ordem constitucional, e que um modus vivendi, consistindo este em viver de acordo com uma norma por ser obrigado a fazê-lo. Os três expressam graus diferentes da aceitação e crença pública em normas, sendo o consenso sobreposto o maior e o modus vivendi o menor. Rawls menciona que muitas sociedades com democracias desenvolvidas ainda não atingiram o consenso sobreposto em torno de valores públicos, tendo alcançado algo similar a um consenso constitucional. Como é a melhor estabilidade possível para uma sociedade democrática marcada pela presença de doutrinas abrangentes, o consenso sobreposto pode ser visto como um fim sempre a ser buscado, o que também pode servir como critério de correção para ações públicas.
} 
fases, uma ampla e uma estrita. O equilíbrio reflexivo restrito ocorre quando uma pessoa alinha seus juízos morais particulares a uma concepção de justiça política que, se expressa publicamente, poderá ser aceitável para os demais membros da sociedade. Um equilíbrio reflexivo amplo ocorre quando, ao revisar seus juízos, uma pessoa considera cuidadosamente outras concepções de justiça e os argumentos que lhes dão base.

$\mathrm{Na}$ Legitimidade como Equidade os Estados são concebidos como os principais agentes internacionais em um ambiente de anarquia internacional moderada em que cada Estado deseja maximizar seus ganhos. A cooperação pode trazer melhores resultados do que a nãocooperação, portanto é uma escolha racional tentar estabelecer um ambiente em que ela (cooperação) possa acontecer com maior segurança. Cada nação possui um conjunto de valores que são considerados de forma análoga àqueles dos indivíduos que se filiam a uma doutrina abrangente em particular na Justiça como Equidade. Os Estados possuem representantes oficiais que precisam levar os valores de sua nação em conta na hora de tomar decisões. Entretanto, atendendo a um desejo racional maior daqueles a que representam estes devem selecionar os valores de sua nação que seriam úteis para o estabelecimento de uma moral publicamente compartilhada internacionalmente, revisando os juízos emitidos de acordo com tal objetivo, não de maneira muito distinta daqueles que usam o equilíbrio reflexivo em sua fase estrita na Justiça como Equidade. Subsequentemente, a revisão de juízos é feita de acordo com os valores compartilhados internacionalmente que ajudem na finalidade do estabelecimento de um ambiente internacional em que a cooperação possa acontecer com maior segurança. Resumidamente, é nisso que constitui o primeiro uso do método do equilíbrio reflexivo na Legitimidade como Equidade, em uma adequação de juízos emitidos (e das razões usadas para emissão destes juízos) por representantes oficiais dos Estados em suas decisões.

O método do equilíbrio reflexivo permite que agentes internacionais que representam os Estados (como diplomatas) considerem os valores nacionais que podem ser apresentados internacionalmente como justi- 
ficativa para as ações (que corresponde na Legitimidade como Equidade ao uso do equilíbrio reflexivo estrito da Justiça como Equidade) e adequar em um segundo momento (que corresponde ao equilíbrioreflexivo amplo) os valores nacionais aos internacionais e às razões oferecidas para a defesa de valores de outros Estados. Os diplomatas e outros agentes oficiais do Estado possuem certa independência inicial de valores nacionais estabelecida por sua condição, mas o vínculo dos valores nacionais não é completamente desfeito, como na solução paliativa de Morgenthau. $\mathrm{Na}$ Legitimidade como Equidade esses valores são apresentados de forma que possam ser reconhecidos de maneira pública, como válidos por outras perspectivas, pois buscam o reconhecimento de sua legitimidade para lidar com questões internacionais. O fato do vínculo de diplomatas e agentes internacionais não ter sido completamente desfeito no primeiro momento, torna-se, quando é atingida a fase do equilíbrio reflexivo amplo, uma vantagem para a estabilidade, pois agora os valores nacionais podem ser revistos de acordo com os argumentos baseados em valores oferecidos por outros Estados, bem como frente aos valores presentes no próprio campo internacional, sendo gradualmente ajustados. Isso, por sua vez, ocasiona uma mudança gradual nos próprios valores nacionais, diminuindo o perigo trazido pelo nacionalismo a tentativa de imposição de valores nacionais como aqueles que seriam válidos internacionalmente.

Como valores que sirvam como pontos fixos provisórios iniciais que operam como elemento análogo aos juízos de repúdio àescravidão e liberdade religiosa (valores a partir dos quais são construídos politicamente os princípios da igual liberdade e da igualdade equitativa de oportunidades), a Legitimidade como Equidade faz uso dos valores abarcados pelo conceito de Jus Cogens (normas cogentes) internacional. No século XX, com a ascensão da doutrina do direito positivo o uso internacional do direito natural caiu em declínio. No direito positivo se considera como direito internacional o direito acordado entre os Estados, que pode ser revogado por uma das partes a qualquer momento e pode versar sobre qualquer matéria. O Jus Cogens internacional contemporâneo teve um desenvolvimento político 
gradual, surgindo de dentro da tradição do direito positivo. Ele é um conceito "positivado" desde a convenção de Viena (que versa sobre os direitos dos tratados). Possuí certa semelhança com o direito natural, tendo, como este, normas que não podem ser derrogadas pelas vontades das partes Entretanto, o Jus Cogens é baseado em considerações políticas e sociológicas, não em uma lei racional natural ou divina. Ele é um conceito dinâmico por não possuir um conteúdo fixo. Normas (sobretudo as que versam sobre a soberania e independência dos povos e aquelas com caráter humanitário) têm adquirido cada vez mais o caráter de Jus Cogens. De acordo com o uso corrente, normas com esse caráter podem (diferente de normas do direito natural) ser revogadas, mas somente por outra norma de Jus Cogens. Considera-se que as normas de Jus Cogens internacional possuem um caráter contratualista e expressam a vontade dos povos como um todo.

O conceito de Jus Cogens é especialmente útil para ser usado como contendo os valores que servirão de pontos fixos iniciais provisórios na Legitimidade como Equidade, pois, dada a maneira como foi estabelecido o uso corrente do conceito, cremos que é possível perceber uma evidência do uso de algo semelhante a um equilíbrio reflexivo por parte dos integrantes da comunidade internacional, estabelecendo a possibilidade de se falar em uma moral internacional mínima mesmo em tempos de ceticismo trazido pela doutrina do direito positivo e das dúvidas acerca da importância da moral para a política internacional levantadas pelo realismo político.

A Legitimidade como Equidade considera que possuem peso real nas decisões internacionais a preocupação com poder e geopolítica, especialmente porque os Estados se portam como se considerando esta preocupação como real, e este não é um fator que pode ser levianamente colocado de lado. Desta maneira, para que a Legitimidade como Equidade possa ser considerada efetiva, ela deverá fazer uso de um conceito que denominamos prudência reflexiva.

O conceito de prudência reflexiva, embora guarde certos traços de astúcia similares a virtu de Maquiavel, consiste em uma virtude muito similar à prudência (phronesis) aristotélica o que torna as prescrições que podem ser feitas a partir da prudência reflexiva superiores àquelas 
de outros tipos de sabedoria prática para atingir o fim estabelecido para a Legitimidade como Equidade. A prudência reflexiva é uma virtude própria dos agentes internacionais. Assim como a prudência aristotélica ela possui certa inexatidão e mostra o que é certo não de maneira universal, mas aquilo que é certo de maneira geral na maior parte das vezes, conciliando a revisão de juízos do uso do equilíbrio reflexivo com as circunstâncias e possibilidades práticas da ação, sem perder de vista a finalidade da Legitimidade como Equidade ${ }^{13}$, da mesma maneira que aquele que possui a virtude na ética aristotélica age de maneira correta com relação à finalidade de atingir o sumo bem (no caso da virtude aristotélica. a felicidade). Tendo em vista a finalidade da Legitimidade como Equidade e as possibilidades trazidas pelas situações práticas, age bem na perspectiva da Legitimidade como Equidade aquele que atinge um justo meio, uma culminância, consistindo esta em promover a finalidade da Legitimidade como Equidade na maior intensidade possível, criando a menor parcela possível de ressentimento e qualquer outro sentimento ou relação que possa prejudicar a confiança necessária para o estabelecimento da finalidade da Legitimidade como Equidade.

Deve-se sempre ter em consideração que condutas que possam ser consideradas legítimas da perspectiva internacional e de uma série de perspectivas nacionais após um exame racional têm mais chances de gerar o tipo de estabilidade que a Legitimidade como Equidade busca estabelecer. Dados os valores e usos correntes no campo internacional a autodeterminação dos povos exige um tratamento equitativo entre eles. É destas duas considerações que a Legitimidade como Equidade retira seu nome. Este comportamento gera uma estabilidade inicial por sua previsibilidade, sua forma e conteúdo, mas para que esta estabilidade se estenda ao longo do tempo outras medidas se tornam necessárias. Assim, a Legitimidade como Equidade é dividida em duas fases. A pri-

13 A saber: O estabelecimento de um ambiente internacional estável alcançado pela busca de um consenso sobreposto realizada usando-se o método do equilíbrio reflexivo. 
meira compreende os ajustes de juízos e comportamentos dos agentes internacionais, de acordo com os critérios que viemos falando até aqui. Chamamos essa primeira fase da Legitimidade como Equidade de fase preliminar. À segunda fase da Legitimidade como Equidade damos o nome de fase institucional. Ela consiste no estabelecimento de instituições nacionais e internacionais que colaborem para a formação de indivíduos, integrando aos valores nacionais a educação no Jus Cogens internacional e a ideia de que seus valores devem ser protegidos e promovidos, dentro dos parâmetros da prudência reflexiva. São indivíduos criados dentro dessas instituições que um dia irão tornar-se representantes dos Estados.

As deliberações realizadas usando-se a prudência reflexiva visam ao estabelecimento de um consenso sobreposto de valores internacionais que terá função análoga ao consenso sobreposto da Justiça como Equidade.

Assim como no caso da Justiça como Equidade, a esperança de uma estabilidade na Legitimidade como Equidade repousa, em grande parte, na tentativa de se atingir um consenso sobreposto. Da mesma maneira que cada cidadão apoia o conteúdo de um consenso sobreposto de acordo com sua própria visão de mundo, se espera que cada Estado possa dar suporte para um consenso sobreposto internacional a partir de sua própria perspectiva, integrando os valores compartilhados internacionalmente aos seus valores nacionais. Como dito por Wenar ${ }^{14}$, o consenso sobreposto é um módulo que pode se integrar a várias visões de mundo.

Wenar afirma ${ }^{15}$ que em um consenso sobreposto, cada grupo defende uma visão de justiça pública e que vai continuar a fazê-lo quer seu grupo aumente ou diminua em poder. Como conceito e fim a ser atingido, o mesmo é válido na Legitimidade como Equidade. Dessa forma, a prudência reflexiva deve atuar para que certos valores sejam preservados se a hierarquia de poder no sistema internacional mudar. Por apelo racional, para que os fins da teoria sejam atingidos, os valores do consenso sobreposto internacional

\footnotetext{
14 WENAR, 2008.

15 Ibid.
} 
devem ser buscados como a melhor alternativa, e o corpus de crença de um Estado/nação particular deve mudar de acordo com essa finalidade, para que os valores do consenso sobreposto não sejam sua segunda melhor escolha, representando valores aos quais recorrem quando não há possibilidade de impor seus próprios, ou a estabilidade que os valores internacionalmente compartilhados podem oferecer perde parte de sua efetividade.

A comunidade internacional possui, é claro, certos valores que são compartilhados de maneira ampla em discursos e como fins políticos, ainda que o nível de coordenação de esforços seja menor do que dentro de Estados e a ausência de um poder único que funcione como árbitro dos conflitos esteja ausente. Considero esses valores em uma analogia à Justiça como Equidade como desempenhando um papel semelhante aos valores publicamente compartilhados em sociedades democráticas. No cenário internacional a ação, para ter maiores chances de ser considerada legítima, deve estar de acordo com os juízos refletidos da comunidade internacional de Estados que consideram a si mesmos como livres e iguais. Se realizada com base em juízos que poderiam ser considerados equitativos, as ações podem gerar maior estabilidade. É dessa ideia que o nome da Legitimidade como Equidade é extraído.

A forma que as instituições nacionais e internacionais devem possuir para atender a finalidade da Legitimidade como Equidade permanece em aberto. De qualquer maneira, quaisquer que sejam as instituições que ajudem a promover a finalidade da Legitimidade como Equidade elas devem ser modificadas ou descartadas de acordo com sua capacidade de atender às exigências de uma virtude que é própria das instituições da Legitimidade como Equidade. À essa virtude damos o nome de equidade reflexiva. Sua qualidade consiste na capacidade de uma instituição ou conjunto de instituições de acompanhar e colaborar com o movimento holístico do equilíbrio reflexivo, influenciando a formação dos indivíduos e por sua vez sendo influenciada de acordo com os valores internacionais e adaptando os valores nacionais aos internacionais.

É com o movimento holístico do equilíbrio reflexivo que a Legitimidade como Equidade perpassa todas as três imagens para as causas do conflito 
como propostas por Waltz em Man, state and war. Na perspectiva das três imagens, o ponto de partida da Legitimidade como Equidade é a terceira. A fase preliminar da Legitimidade como Equidade começa com alteração de conduta e juízos dos agentes internacionais, no ambiente internacional de forma a afirmar os valores do Jus Cogens internacional. Na fase institucional da Legitimidade como Equidade as instituições internacionais e nacionais são modificadas com o objetivo de manter a estabilidade ao longo do tempo, ocorrendo na modificação e criação de novas instituições um movimento da terceira para a segunda imagem. Quando as pessoas são formadas nestas instituições temos um deslocamento da segunda para a primeira imagem e um movimento de retorno à terceira imagem quando alguma destas pessoas torna-se, em qualquer situação, representante de seu Estado, dando um novo início ao ciclo sempre em movimento que visa alcançar um consenso sobreposto moral internacional, um objetivo que permanece sempre em aberto, pois é um fim que funciona como critério de correção e aperfeiçoamento.

Consideremos novamente as alternativas "standard" de estabilidade internacional.

Dentre as alternativas "standard" é praticamente um ponto pacífico que aquela oferecida por um governo internacional ou instituição internacional com o uso exclusivo da força, em um cenário adequado, seria a melhor de todas as alternativas possíveis. Entretanto, os usos e costumes correntes nas relações internacionais (incluindo a visão que os Estados têm de sua própria identidade como livres e iguais em sua autodeterminação), os nacionalismos e a falta de condutas que assegurem uma aplicação dos valores internacionalmente compartilhados fazem com que o cenário adequado para instauração desta alternativa não possa surgir com facilidade ${ }^{16}$. Como poderia ser considerado opressor e gerar

\footnotetext{
16 Embora não seja seu fim último, a Legitimidade como Equidade pode ela mesma ser vista como propondo uma maneira pela qual um cenário transitório adequado para a instauração de uma instituição internacional com o uso exclusivo da força. Todavia, cremos que os critérios de conduta como delineados pela teoria não precisam levar para esta forma específica e podem ser de uso simples e imediato, tendo como ponto de partida os arranjos internacionais correntes.
} 
instabilidade por causa de revoltas com cunho nacionalista, a Legitimidade como Equidade rejeita esta alternativa. A estabilidade oferecida por uma balança de poder entre potências, sem que esta seja considerada um valor, como no caso das potências europeias durante a modernidade (como arguido por Morgenthau em A política entre as nações), requer muita habilidade e constante vigilância decorrentes do fato óbvio de que se o equilíbrio de poder for alterado, a estabilidade pode se perder, pois aquele que agora tem vantagem pode realizar condutas agressivas ou impor sua vontade aos demais gerando ressentimento. É a possibilidade franca de gerar ressentimento e a necessidade de um nível elevado de vigilância que, em última análise, fazem com que a Legitimidade como Equidade também recuse a alternativa da estabilidade oferecida por uma balança de poder buscada como um valor. Se buscada como um valor por potências envolvidas em um jogo de poder deve-se esperar a instabilidade gerada pelas disputas em territórios pertencentes a Estados que não são protagonistas no jogo de poder. Uma paz imposta hegemonicamente carece do perigo do ressentimento, além da possibilidade da falta de legitimidade que podem facilmente ser considerados fatores de instabilidade. Mesmo a habilidade e moderação no uso do poder e a astúcia em fazer concessões, como teorizadas por Carr, podem ser ineficazes quando grandes potências defrontam nacionalismos muito radicais. Além disso, algum padrão moral pode ser útil para saber quando usar a força.

Embora ofereça uma proposta de estabilidade ancorada em um consenso sobreposto, o diferente contexto de aplicação e uma análise metaética mostram que a Legitimidade como Equidade afasta-se definitivamente da Justiça como Equidade. Uma análise como essa revelaria que a Justiça como Equidade é uma teoria coerentista e deontológica enquanto a Legitimidade como Equidade é uma teoria coerentista e teleológica.

É sabido que Rawls possui sua própria teoria para a relação entre diferentes povos, com uma proposta de estabilidade, a saber: o Direito dos Povos. A Legitimidade como Equidade também se afasta do Direito dos Povos. Ela não o faz pelo seu contexto de aplicação, mas uma análise me- 
taética mostraria que o Direito dos Povos (como a Justiça como Equidade) é uma teoria coerentista e deontológica enquanto a Legitimidade como Equidade é (conforme havíamos dito) uma teoria coerentista e teleológica. Além disso, uma investigação realizada sob a perspectiva das três imagens de Waltz também mostraria que a Legitimidade como Equidade se distancia do Direito dos Povos. O Direito dos Povos é uma teoria a ser usada por povos liberais que se filiam à Justiça como Equidade que querem garantir a subsistência de suas instituições na busca de princípios para suas relações com outros povos e possui sua culminância quando todos os povos forem liberais razoáveis ou decentes, o que torna o Direito dos Povos como uma teoria que localiza a causa dos conflitos na estrutura e organização dos Estados, sendo uma teoria de segunda imagem. Embora possua considerações relevantes para questões relativas a todas as três imagens de Waltz (como em Man, state and war), seu ponto de partida é a segunda imagem. A Legitimidade como Equidade tem como Ponto de partida a terceira imagem. Isso é evidente especialmente na sua fase preliminar. Na sua fase subsequente fica claro o seu movimento para as duas outras imagens e o retorno para a terceira, evidenciando seu caráter holístico.

Com o suporte e os elementos de uma teoria como a Legitimidade como Equidade, que faz uso dos conceitos de equilíbrio reflexivo e consenso sobreposto de uma maneira singular, e tendo em vista as considerações que fizemos aqui, a proposta que fizemos inicialmente, parece justificada.

\section{Considerações finais}

Cremos que o potencial de estabilidade trazida por políticas que seriam realizadas de acordo com os parâmetros da Legitimidade como Equidade trariam mais estabilidade e aumentariam as possibilidades de cooperação em mais casos do que aquelas políticas que consideram como viáveis que a estabilidade internacional seja oferecida dentro da conjuntura de uma das alternativas que denominamos "standard", no arranjo corrente da política internacional. 
Políticas que estejam dentro da forma que seria recomendada a partir da Legitimidade como Equidade, uma vez que não buscam necessariamente a instauração de uma entidade internacional com uso exclusivo da força e não contradizem de forma abrupta valores nacionais razoáveis, que podem ser considerados fundamentais para a identidade de um povo (além de importantes na formação de certas instituições nacionais básicas), podem, a nosso ver, ser buscadas com mais facilidade pelos Estados, pois encontrariam maior suporte interno nos Estados. Logo, a Legitimidade como Equidade possui maior chance de ser bem-sucedida em sua aplicabilidade do que a única alternativa que poderia oferecer uma estabilidade de maior qualidade.

Por outro lado, a qualidade da estabilidade que a Legitimidade como Equidade pode oferecer é maior do que aquelas que as outras três alternativas "standard" poderiam e o uso inicial de práticas como prescritas pela teoria não é complicada, pois ficaria dentro de limites correntes nas práticas internacionais.

O que diferencia práticas que estariam de acordo com recomendações que poderiam ser feitas a partir da Legitimidade como Equidade daquelas das três alternativas "standard" que não incluem o estabelecimento de uma instituição internacional com uso exclusivo da força é a finalidade. Tal finalidade é, em um primeiro momento, sustentada pela prudência reflexiva, que é uma virtude prática.Portanto, a força inicial da Legitimidade como Equidade está na possibilidade de adequar sua finalidade ideológica às práticas e valores internacionais correntes. Com o tempo e as práticas corretas, a Legitimidade como Equidade oferece uma estabilidade de maior qualidade do que as alternativas "standard", pois passa a ser garantida por valores comuns aos Estados.

Além disso, todos os âmbitos que poderiam ser causa de conflito, representado pelas três imagens de Waltz, são considerados na Legitimidade como Equidade.

Todas as vantagens da Legitimidade como Equidade só são possíveis se levarmos em conta o papel fundamental dos usos teóricos do equilíbrio reflexivo e do consenso sobreposto. 
Apesar de não haver (e na ausência de) uma instituição internacional com uso exclusivo da força um consenso sobreposto de valores compartilhados oferece a melhor alternativa de estabilidade.

O equilíbrio reflexivo por sua vez, faz com que a solução para as causas do conflito que tenha como fim alcançar um consenso sobreposto perpasse todas as três imagens de Waltz. Ela teria início na terceira imagem, com as práticas internacionais, passaria ao ambiente interno com mudanças de políticas e instituições para adequá-las aos juízos refletidos e, então, retorna ao ambiente internacional com indivíduos formados nessas instituições que agora poderão atuar como representantes oficiais de Estados.

Como dissemos anteriormente, com uma base fornecida por uma teoria que faz uso dos conceitos de equilíbrio reflexivo, a proposta que apresentamosaquil', parece justificada. Entretanto resta saber se o uso dos elementos do equilíbrio reflexivo, do consenso sobreposto e da prudência reflexiva na Legitimidade como Equidade pode resistir às objeções que podem ser levantadas contra estes conceitos tanto em uma perspectiva que tenha como ponto de partida as teorias em que aparecem originalmente (a Justiça como Equidade e a Ética Aristotélica) quanto da maneira como aparecem na própria Legitimidade como Equidade.

É sabido, por exemplo, que o uso do equilíbrio reflexivo da maneira como aparece na Justiça como Equidade sofreu notórias objeções como as críticas sobre a capacidade e uso de intuições morais, a crítica sobre o apelo a fatos e determinada visão de natureza humana pelo construtivismo rawlseano e seu uso do equilíbrio reflexivo amplo bem como diversas críticas epistemológicas ao equilíbrio reflexivo da Justiça como Equidade. Deve-se apurar de maneira mais profunda se e como a Legitimidade como Equidade poderia resistir a críticas semelhantes.

\footnotetext{
17 A de que a estabilidade oferecida pela busca de um consenso sobreposto (moral) de Estados, que se procura atingir pelo método do equilíbrio reflexivo, é mais eficiente do que a baseada em um equilíbrio de poder ou ações prudenciais e, dados os arranjos internacionais correntes, pode ser alcançada com mais facilidade, e pode ainda ser mais facilmente aceita do que a criação de um governo mundial ou instituição internacional com uso exclusivo da força.
} 
Até este ponto a Legitimidade como Equidade é uma teoria que está em seu estágio inicial de desenvolvimento. Ela deve enfrentar objeções como as descritas acima com a finalidade e desenvolver seu sistema de justificação, modificando e adicionando novos conceitos e descartando outros.

\section{Referências}

ARISTÓTELES. Ética à Nicômaco. Tradução de Leonel Vallandro e Gerd Bernheim. São Paulo: Abril Cultural, 1973. (Coleção os pensadores).

ARISTÓTELES. Eudemian Ethics: books I, II and VIII. Translated with a commentary by Michael Woods. 2nd ed. Oxford: Claredon, 2005.

ARISTÓTELES. Política. Tradução de Mário de Gama Kury. Brasília: UnB, 1985. AUDARD, C. John Rawls. Montreal: McGill-Queen's University Press, 2007.

BARBOSA, A. S. Jus Cogens: gênese, normatização e conceito. Revista Eletrônica de Direito Internacional, Belo Horizonte, v. 14, 2014.

BEITZ, C. R. Political theory and international relations. Princeton: Princeton University, 1979.

BRASIL. Decreto $n^{\circ} 7.030$, de 14 de dezembro de 2009. Promulga a Convenção de Viena sobre o Direito dos Tratados, concluída em 23 de maio de 1969, com reserva aos Artigos 25 e 66. Brasília: Presidência da República, 2009. Disponível em: http://www.planalto.gov.br/ccivil_03/_at02007-2010/2009/decreto/ d7030 .htm. Acesso em: 25 jun. 2016. https://doi.org/10.18840/1980-8860/ rvmd.v6n1p22-46

CARR, E. H. Vinte anos de crise: uma introdução aos estudos de relações internacionais. Tradução de Luiz Alberto Figueiredo Machado. 2. ed. Brasília: UnB, 2001.

CARVALHO, L. A. Introdução ao estudo das relações internacionais. Porto Alegre: Síntese, 2003.

ELMAN, C.; JENSEN, M. A. (ed.). Realism reader. London: Routledge, 2014.

FREEMAN, S. Rawls. London: Routledge, 2007.

GELLNER, E. Naciones y nacionalismo. Madrid: Alianza Universidad, 1993. 
GRIECO, J. Anarchy and the limits of cooperation: a realist critique of the newest liberal institutionalism. International Organization, Cambridge, v. 42, n. 3, p. 485-507, 1988. https://doi.org/10.1017/s0020818300027715

HASLAM, J. A necessidade é a maior virtude: o pensamento realista nas relações internacionais. São Paulo: Martins Fontes, 2006. https://doi.org/10.1590/ S0102-85292008000200007

JACKSON, R.; SORENSEN, G. Introdução às relações internacionais. Rio de Janeiro: Jorge Zahar, 2007.

JOHN RAWLS. In: WENAR, L. Stanford Encyclopedia of Philosophy. Stanford: Stanford, 2008. Disponível em: https://plato.stanford.edu/entries/rawls/ . Acesso em: 12 maio 2011.

KEIM, W. D. Ethics, morality and international affairs. Lanham: University Press of America, 2000.

MARTIN, R.; REIDY, D. A. (org.). Rawls law of peoples: a realistic utopia? 3rd ed. Oxford: Blackwell, 2008.

MCQUEEN, A. On Hans J. Morgenthau's 'The Twilight of International Morality'. Ethics, [s. l.], v. 125, n. 3, p. 840-842, 2015. https://doi.org/10.1086/679546

MOREIRA, A. Teoria das relações internacionais. Coimbra: Almeida, 1999.

MORGENTHAU, H. J. A política entre as nações: a luta pelo poder e pela paz. Tradução de Oswaldo Biato. Brasília: UnB, 2003.

MORGENTHAU, H. J. Politics among nations: the struggle for power and peace. 2nd ed. New York: Knopf, 1954.

NASSER, S. H. Jus Cogens ainda esse desconhecido. Revista Direito GV, São Paulo, v. 1, n. 2, p. 161-178, 2005.

NATIONALISM. In: MISCEVIC, N. Stanford Encyclopedia of Philosophy. Stanford: Stanford University, 2001. Disponível em: https://plato.stanford. edu/entries/nationalism/. Acesso em: 02 nov. 2014.

NIETO-NAVIA, R. International peremptory norms (Jus Cogens) and international humanitarian law. [S. l.: s. n., 2010]. Disponível em: http://www.iccnow. org/documents/WritingColombiaEng.pdf . Acesso em: 29 jul. 2015. https:// doi.org/10.1017/cbo9781139976664.004

OLIVEIRA, N. F. Rawls: filosofia. Rio de Janeiro: Jorge Zahar, 2003. (Coleção Passo a Passo, v. 18). 
OLIVEIRA, F. N. Realismo político e cooperação internacional: valores internacionais e consenso sobreposto como alternativa de estabilidade. 2016. Tese (Doutorado em Filosofia) - Programa de Pós-Graduação em Filosofia, Pontifícia Universidade Católica do Rio Grande do Sul, Porto Alegre, 2016. Disponível em: http://tede2.pucrs.br/tede2/handle/tede/7219. Acesso em: 05 nov. 2019. https://doi.org/10.31789/imscid-2019-001

ORIGINAL POSITION. In: FREEMAN, S. Stanford Encyclopedia of Philosophy. Stanford: Stanford University, 1996. Disponível em: https://plato.stanford. edu/entries/original-position/. Acesso em: 11 maio 2011.

POLITICAL REALISM. In: MOSELEY, A. Internet encyclopedia of philosophy. [London, 2019]. Disponível em: https://www.iep.utm.edu/polreal/ . Acesso em: 22 jan. 2015.

POLITICAL REALISM IN INTERNATIONAL RELATIONS. In: KORABKARPOWICZ, W. J. Stanford Encyclopedia of Philosophy. Stanford: Stanford University, 2010. Dsponível em: http://plato.stanford.edu/archives/fall2010/ entries/realism-intl-relations/. Acesso em: 21 out. 2011.

RAWLS, J. A theory of justice: original edition. Cambridge: Harvard University, 2005.

RAWLS, J. Justiça como equidade: uma reformulação. Tradução de Cláudia Berliner. São Paulo: Martins Fontes, 2003.

RAWLS, J. O direito dos povos. Tradução Luís Carlos Borges. São Paulo: Martins Fontes, 2001.

RAWLS, J. O liberalismo político. 2. ed. Tradução de Dinah de Abreu Azevedo. São Paulo: Ática, 2000.

RAWLS, J. Political liberalism: expanded edition. New York: Columbia University, 2005.

RAWLS, J. The law of peoples: with the idea of public reason revised. Cambridge: Harvard University, 2002.

RAWLS, J. Uma teoria da justiça. Tradução de Almiro Pisetta e Lenita Esteves. São Paulo: Martins Fontes, 2000.

REALISM (INTERNATIONAL RELATIONS). In: WIKIPEDIA: the free encyclopedia. [San Francisco: Wikimedia Foundation, 2019]. Disponível em: http://en.wikipedia.org/wiki/Realism_(international_relations). Acesso em: 22 jan. 2015. 
REFLECTIVE EQUILIBRIUM. In: DANIELS, N. Stanford Encyclopedia of Philosophy. Stanford: Stanford University, 2003. Disponível em: https:// plato.stanford.edu/entries/reflective-equilibrium/. Acesso em: 31 out. 2016. ROUSSEAU, J-J. Discurso sobre a origem das desigualdades. Tradução de Maria Lacerda de Moura. São Paulo: [s. n.], 2011. E-book. Disponível em: http://www. ebooksbrasil.org/adobeebook/desigualdade.pdf . Acesso em: 05 nov. 2019. SCANLON, T. Rawls on justification. In: FREEMAN, S. (ed.). The Cambridge companion to rawls. Cambridge: Cambridge University, 2002. p. 139-167. https://doi.org/10.1017/ccol0521651670.004

SEITENFUS, R. A. Relações internacionais. Barueri: Manole, 2004.

SINGER, J. D. The level-of-analysis problem in international relations. World Politics, Baltimore, v. 14, n. 1, p. 77-92, 1961.

SMITH, A. Identidade nacional. Lisboa: Gradiva, 1997.

WALTZ, K. N. Man, state and war: a theoretical analysis. 4th ed. New York: Columbia University, 1965.

WALTZ, K. N. Theory of international politics. New York: Waveland, 2010. Edição original em 1979.

\section{Endereço Postal}

\section{Fernando Nunes Oliveira}

Universidade Federal de Pelotas - UFPel

Instituto de Filosofia, Sociologia e Política

|Departamento de Filosofia

Caixa Postal 354 | CEP 96001-970 | Pelotas, RS 